\title{
Linking to the real world: contextual teaching and learning of statistical hypothesis testing
}

\author{
Jeanne Marie L. Lago ${ }^{1}$ and Ruth A. Ortega-Dela Cruz ${ }^{2}$ \\ ${ }^{1}$ Department of Education, Division of Batangas, Cuenca Senior High School, \\ Cuenca, Batangas, Philippines \\ ${ }^{2}$ University of the Philippines Los Baños, Laguna, Philippines
}

The study used experimental research design to randomly selected senior high school students in analysing their attitude and achievement in statistics when contextual teaching is implemented. In addition to structured questionnaires, semistructured interviews with the students were also conducted to provide rich descriptions about learning experiences with contextual teaching. Results revealed that students have positive attitude towards statistics and that students learn better with contextualized instruction than direct instruction. With this, contextualized instruction must be promoted in teaching statistics. By linking it to the real world, students would be able to view statistics more than just a subject. Thus, it makes the statistical hypothesis testing learning more enjoyable and exciting.

Keywords: contextual teaching and learning, effectiveness, hypothesis testing, senior high school, statistics

ARTICLE DETAILS

LUMAT General Issue Vol 9 No 1 (2021), 597-621

Received 15 April 2021 Accepted 28 June 2021 Published 12 August 2021

Pages: 25

References: 46

Correspondence: raortegadelacruz@up.edu.ph

https://doi.org/10.31129/ LUMAT.9.1.1571

\section{Introduction}

In a data-driven world, statistics plays a vital role in all fields of work. Statistics being embedded within the mathematics curriculum deals with collecting, organizing, summarising, and analysing data in order generate relevant conclusions. With proper application of statistics, discoveries are made, and policies become more relevant and give answers to different social problems. These are some of the reasons why statistics has always been part of any of the school curriculum. Despite knowing these overriding contributions the statistics has on individual and society, it is hated by learners who are not into numbers or quantitative data, especially those students who are more into social sciences (Prayoga \& Abraham, 2017). When they are asked to memorize formulas, they tend to pay attention less (Ramsey, 1999). Because of these formulas and rules involved in statistics lessons, students tend to develop negative attitudes and concerns towards the subject (Altintas \& Ilgün, 2017). Students had misconceptions about basic statistical concepts such as in measures of central tendency and spread. Researchers have also shown that these students experienced fear and anxiety towards the subject (Zieffler, Garfield, Alt, Dupuis, Holleque, \& 
Chang, 2008).

Dealing with numbers for students to come up with informed decisions is just one of the major skills they have to acquire upon graduation. In the Philippine K to 12 program of the Department of Education, Statistics and Probability is offered as a core subject being taken by all senior high school students in all tracks. It cannot be denied that there are students who try to avoid mathematics, thus they are taking up a strand or program in senior high school with less mathematics. One of these strands is Humanities and Social Sciences strand. Students who are to take up education, criminology, psychology and other social science programs in college belong to this strand.

After two years of offering and teaching the subject to mostly 16-year-old Grade 11 students (i.e., First Year Senior High School), they scored below mastery level in the recorded fourth quarterly examinations. As prescribed by the curriculum guide, the fourth quarter must include the teaching and learning of hypothesis testing. In school year 2016-2017, they scored 52.6, while in school year 2017-2018, they scored an average of 49.3. Students are generally not meeting the standard of 75 percent. Moreover, when this mean percentage score is compared with the other subjects, it is one with low rank. Adding to this is the observed negligence of students in submitting requirements. The completion rates of seatwork and homework appeared lower than usual. The students truly struggle with the content and feel that they are exerting effort and that exerting effort is not productive.

In this sense, teachers must also be aware of their crucial role in facilitating the learning of their students. Recognizing the importance of teaching and learning statistics, teachers must be able to teach the subject well in the context of problem solving using real data. Garfield (1995) as cited in Larwin and Larwin (2011) suggested the use of variety of strategies in teaching statistics by providing students with activity-based and computer-assisted instructions.

To ensure quality delivery of instruction, the Philippine Department of Education promotes active learning as emphasized in the K-12 program. It has suggested some strategies to be used in different subject areas to encourage learners to be active. These strategies, in general, are student-centred, thus, encouraging learners to become active as much as possible. One of the strategies being promoted by the department is the use of contextualization. Contextualization is defined as a set of different instructional strategies designed to link content by focusing teaching and learning on "concrete applications in a specific context that is of interest to the student" (Mazzeo, 
Rab, \& Alssid 2003) as cited in Perin (2011). With contextualization, a connection between the content and skill is taught with real-world events. Applying contextualized instruction, improvements in attitude and achievement have been discovered in several studies (Haryanto \& Arty, 2019; Syahputri \& Mariyati, 2019; Suryawati \& Osman, 2018; Shodiq \& Ihsan, 2017; Qudsyi, Wijaya, \& Widiasmara, 2017)

Methods in statistics can be used in different social science situations. This makes statistics crucial to the students and graduates under the Humanities and Social Sciences strand. As teachers, they are to design and develop relevant activities to ensure learning. In this study, contextualized instruction was employed in teaching and learning hypothesis testing. The teacher used issues, events, activities, and authentic materials related to the learners to meet their needs on the subject. The study specifically sought answers to the following research questions:

1. Is there a significant difference between the attitudes (value, interest, and effort) of students towards learning statistical hypothesis testing prior and after the implementation of contextual teaching?

2. Is there a significant difference between achievement of students towards learning statistical hypothesis testing prior to and after the implementation of contextual teaching?

Generally, the study aimed to analyse the students' attitude and achievement when contextual teaching is implemented. It specifically (i) determined the attitudes (value, interest, and effort) of students towards learning statistics; (ii) compared the attitudes (value, interest, and effort) of students towards learning statistical hypothesis testing prior and after the implementation of contextual teaching; and (iii) analysed the difference in the achievement of students on hypothesis testing prior and after the implementation of contextual teaching.

\subsection{Literature review}

The importance of statistics has been recognized by different institutions and business organizations as defined by the American Statistical Association (ASA) - "Statistics is the science of learning from data, and of measuring, controlling and communicating uncertainty (Wild, Utts, \& Horton, 2018). It is a way to understand the data that is collected about people and the world. This is why teaching statistics has been part of the school curriculum. In the Philippine education system, senior high school 
students are required to take it as part of any program of specialization. Statistics and Probability is taken by all senior high schools as a core subject. Before the implementation of the K-12 curriculum, statistics was taught in public high schools during the last quarter of the third year (TeacherPH, 2020). The subject has been taken for granted when most mathematics teachers cover topics involving algebra. Zieffler et al. (2008) reviewed literatures on teaching introductory statistics to college-level students and found not such good results. Students had misconceptions about basic statistical concepts such as in measures of center and spread. Researchers have also shown that these students experienced fear and anxiety towards the subject.

Recognizing the importance of teaching and learning statistics, teachers must be able to teach the subject well in the context of problem solving using real data. One of the strategies being promoted by the Philippine Department of Education is the use of contextualization.

\subsubsection{Contextualized teaching and learning (CTL)}

Advanced statistics and other theoretical sciences are often taught purely using the lecture format, which promotes passivity and isolation in students (Rosenthal, 1995 in Duru, 2010). Direct instruction has been the traditional way of teaching mathematics where procedures and rote memorizations are involved. Students are often bombarded with procedures and processes in subjects such as statistics after which they are given drills.

Opposing this traditional way of direct instruction is having the students engaged in activities in the context of the lesson's application to the real world. Contextualization involves strategies that link learning of a skill to its application in a context that is interesting to the students. It allows students to value and make meaning to what they learn in school (Mouraz, \& Leite, 2013). Baker, Hope, and Karandjeff (2009) stated that an authentic context helps the learners see the relevance of information and creates a pathway for them to understand the material. Since students find learning relevant, with contextualization, students' confidence, enthusiasm and interest in long-term goals and education are enhanced (Bird, Livesey \& Simon, n.d.).

The contextual teaching and learning (CTL) was described by Johnson (2002) as a holistic system that it is made up of several components. These components include: 1) making meaningful connections, 2) doing significant work, 3) collaborating, 4) critical and creative thinking, 5) nurturing the individual, 6) reaching high standards, 
and 7) authentic assessment. She argues that all these components must build a network by which students are able to make meaning and retain information. In the implementation of CTL, other elements have to be considered. In connection to this, Hidayah (2017) suggested that activation of existing knowledge requires acquiring knowledge by studying the whole world first, then paying attention to the details. Understanding, practicing, experiencing the knowledge and reflecting the strategy for developing knowledge have to be looked into when practicing CTL.

Out of these CTL principles, REACT was developed by Crawford (2001) and implemented in America. REACT (relating, experiencing, applying, cooperating, and transferring) is a set of teaching strategies that is used to make students establish their sense of interest, confidence, and a need for understanding. Relating is the most dominant element in contextual teaching strategy. It suggests that students' learning must happen in the context of one's life experiences or pre-existing knowledge. Experiencing in contextual approach is a strategy that tries to make students active learners (Misteni, \& Baehaqi, 2016). Applying strategy can be defined as learning by putting the concepts learned to use. Through problem solving activities, students may apply what they have learned and practiced. For students to handle more complex problems, allowing them to work in groups is suggested with little outside help (Pintrich \& Schunk, 1996 in Crawford, 2001). This is the strategy of cooperating. This strategy refers to learning in the context of sharing, responding, and communicating with other learners (Crawford, 2001). The last strategy is transferring. Transferring is a teaching strategy that allows students to use knowledge in a new context. In this case, the situation or task has to be authentic and has not been done in class.

The context that must be assumed to ensure maximized learning is crucial in CTL. Perin (2011) asserted that students' experiences are more valued in contextualized classrooms. Ambrose, Davis and Ziegler (2013) came up with a framework of CTL as follows. 


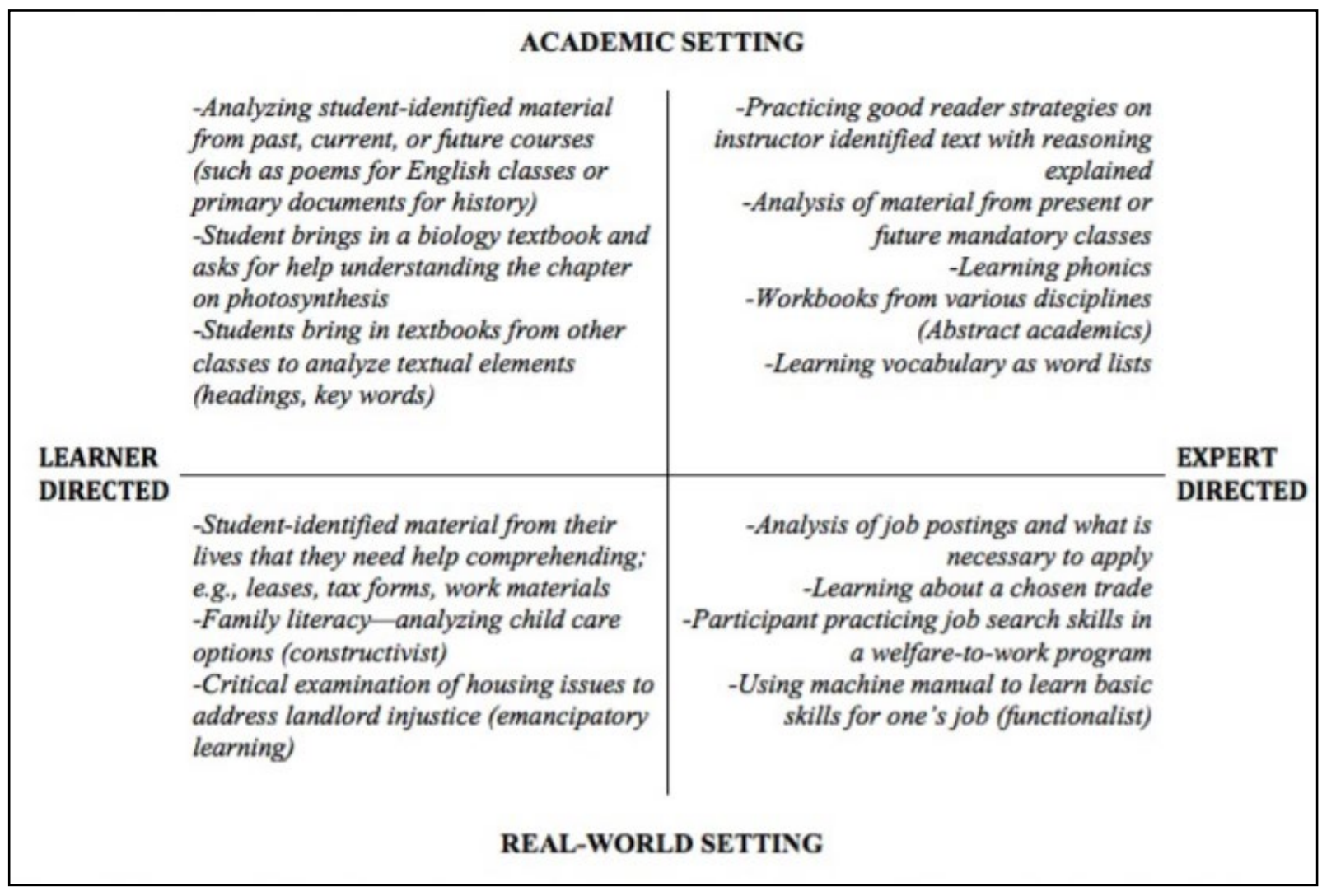

Figure 1. Contextualized Teaching and Learning Framework (Ambrose, Davis \& Ziegler, 2013)

The framework suggests that contextualized teaching and learning is done when materials that are student-led or identified are used in the classrooms. Another way is to offer a program that focuses on real-world settings and integrates academic content into it. In designing the teaching guide, the continuum shown above was considered.

\subsubsection{Attitudes towards mathematics}

Besides ability, achievement is also influenced by attitude. Attitude as a concept has implications to both the learner and teacher. Researchers showed that positive attitude leads to better performance. Mensah, Okyere, and Kuranchie (2013) stated that through positive experiences and reinforcement, a student develops positive attitude towards mathematics.

Furthermore, attitudes of students regarding statistics must be given attention for several reasons as stated by Gal, Ginsburg and Schau, (1997). These attitudes have role in the teaching and learning process in influencing student statistical behaviour and its influence on whether a student will pursue further statistics courses. In this sense, teachers should be aware that student's attitudes towards the subject is 
something that they should take into account. It is important for teachers to assess the student's attitude towards statistics for further research and improvement of instruction.

Attitudes such as effort, value and interest of learners are important for them to achieve more in mathematics. To achieve this, one is required to exert effort. Students' effort is critical to their learning (Carbonaro, 2005 in Karabiyik \& Mirici, 2018).

Both interest and value predict mathematics achievement (Kim, Jiang \& Song, 2012). Students perform better when they are into a task and when they find it useful. Between the two, it was found out that interest has greater predictive power of achievement than value. High achievers also develop more positive attitude towards mathematics (Mata, Monteiro \& Peixoto, 2012).

Attitude towards mathematics is caused by other factors such as positive experiences students have in class (Mensah, Okyere, \& Kuranchie, 2013). Among the second- and third-year classes in Senior High School, it was found out that attitude and performance are positively correlated. Hence, it is recommended that teachers must provide activities that are appealing and interesting to the students. Once positive attitudes are developed, it will then lead to better performance.

\subsubsection{Effectiveness of CTL}

Contextualization has already posed several advantages to student achievement and attitude in different subject areas. Using CTL approach against direct instruction, it was found out that students learn better when instructions are contextualized (Selvianiresa \& Prabawanto, 2017). In terms of attitude, learning science becomes more interesting, challenging, and cooperative (Suryawati, Osman, \& Meerah, 2010). From three secondary schools in Indonesia, results showed that problem solving was improved through contextualized instruction. Through hands-on activities provided, students learn to apply concepts in real life (Suryawati, Osman \& Meerah, 2010).

Studies also showed positive results of the use of CTL in mathematics. Representational ability may also be improved using CTL modules (Surya \& Saragih, 2017). In the study, a CTL module was developed based on the context of Aceh culture, a unique Indonesian culture. As a result, students responded positively to the material developed, which arouse their interest in learning which then made teaching effective. Moreover, results showed that there was an increase in the representational ability of the students in topics in algebra. 
The results of a multiple case study conducted by Valenzuela (2018) illustrated the effectiveness of using contextualized curriculum in college. Considering statistics, it may be taught in different contexts. One of which is teaching statistics in the context of biology. Hypothesis testing and estimation were included in the beginning of the semester making students motivated by seeing the importance of statistics in the science or scientific method (Seier \& Joplin, 2010). With this, activities that motivate students were easier to find. In this case, teachers are said to benefit from it.

Lastly, the study of Mam, Domantay, and Rosals (2017) revealed that the use of contextualized and localized teaching increased the scores of the students in statistics. They suggested the development of an authentic, contextualized and localized instructional material in statistics subject to improve the performance of the students.

\section{Materials and methods}

\subsection{Research design}

An experimental research design was utilized in the study. This design aims to test the cause and effect of specific treatment by comparing end results between a control and an experimental group (Fraenkel, Wallen, \& Hyun, 2011). With this design, a group was randomly assigned as the experimental group that received contextual teaching of statistical hypothesis testing. The researcher manipulated the independent variable by providing different learning activities to two groups of students. One received the contextualized instruction, while the other was taught using direct instruction. In the end, its effect was determined by comparing the post-test scores of the respondents.

\subsection{Subjects of the study}

From the total population of 166 Grade 11 students, 72 students were randomly selected for the study. They were under the Humanities and Social Sciences program, a strand that offers subjects with specialization on Social Sciences. The students were divided into two groups, each group was composed of 36 students who have the same level of performance in Statistics. Match pairing was based on their third-quarter grade in Statistics. Basically of the 72 respondents, 36 students were assigned to the experimental group and another 36 students were assigned to the control group. 


\subsection{Instrumentation}

In order to meet the objectives of the study, research instruments were developed such as the researcher-made test and the survey questionnaires for determining the attitudes.

Pre/Post Test on Statistical Hypothesis Testing. Using the competencies expressed in the Senior High School Statistics and Probability Curriculum Guide, a table of specification was made by the researcher which served as a guide in the development of the pre/post-test (see Appendix). An item was created for each competency. The researcher-made test was checked by the principal and the master teacher in mathematics. The prepared test was validated by checking the item against the corresponding learning competency in the curriculum guide. The researcher also conducted test of reliability with test-retest and Cronbach-Alpha method and the result got a total degree (0.80) with a reliability factor of 'good'.

Determining Student's Attitudes towards Statistics. To measure the attitudes of learners towards the subject, the Survey of Attitudes Towards Statistics (SATS-36) by Schau, Stevens, Dauphinee, and Vecchio (1995) as used by Hommik and Luik (2017) was utilized. Only three of the six aspects included in the survey were adopted. These three aspects including interest, value, and effort were found appropriate in measuring the attitude towards statistics using localised and REACT strategies under CTL. Under each aspect are nine, four and another four items respectively. Each item was rated using a seven-point response scale. Higher scores correspond to more positive attitudes. Negative words and statements in the survey were modified. The adopted and modified test was pilot tested on 30 senior high school students. Results were tested for reliability through Cronbach's alpha. The value of Cronbach's alpha greater than 0.7 is considered acceptable and reliable (Panayides, 2013). Results of the pilot testing showed an acceptable Cronbach's alpha values of $0.74,0.88,0.79$ for the value, interest, and effort values respectively. Short semi-structured interviews with the students were also conducted to provide rich descriptions of their learning experiences with a contextual teaching.

Intervention: Designing and Contextualizing Teaching Guide on Statistical Hypothesis Testing. ADDIE model was adopted in creating the instructional material. Syatriana (2013) described each phase which includes analysis, design, development, implementation and evaluation.

Firstly, background information about the students were gathered. Secondly, the design phase involved the identification of CTL on which the teaching guide was 
based. This follows the 5 E's constructive instruction model which stand for engage, explore, explain, elaborate/extend, and evaluate (Bybee, 2014).

The development of teaching guide involved the use of real data, actual findings and reports downloaded online. The guide was developed and validated by two mathematics teachers from the public high school and another two mathematics teachers from a private high school. The developed teaching material was preimplemented to another group of students, who were not part of the subjects of the study.

Finally, it was implemented in the experimental group. Feedback was collected through interviews with the students under the experimental group. The short interview took a minimum of three and maximum of 10 minutes per student. It determined the students' individual perceptions based on their experience with the contextualised instruction used in Statistics. Also, the effectiveness of the developed teaching material was evaluated through a post-test.

The Contextualized Teaching Guide. Using the prescribed lesson plan format in designing lesson plans (DepEd Order No. 42, s. 2016), and elements of REACT (relating, experiencing, applying, cooperating, transferring), the following teaching guide was created (Table 1). The lessons started with identifying objectives and end with evaluation.

Table 1. Summary of the guide for contextual teaching

\begin{tabular}{|c|c|}
\hline Lesson & $\begin{array}{l}\text { Description of Activities } \\
\text { (REACT strategy used) }\end{array}$ \\
\hline $\begin{array}{l}\text { 1.Introduction to } \\
\text { Hypothesis } \\
\text { Testing }\end{array}$ & $\begin{array}{l}\text { Engage (Relating): } \\
\text { 1. Have the learners watch the video clip, "Bad Effect of Social Media". } \\
\text { 2. Have them grouped into } 5 \text {. Allow them to share their insights about the video clip } \\
\text { and answer some questions. } \\
\text { Explore (Relating, Cooperating): } \\
\text { Present a STAT report. } \\
\text { In groups, make learners identify the steps or processes must be done to come up } \\
\text { with a decision. } \\
\text { Explain (Cooperating): } \\
\text { Answers will be published and put together. } \\
\text { Discussion follows. } \\
\text { Elaborate: } \\
\text { 1. Discussion follows about the three methods used to test hypotheses, the general } \\
\text { steps in hypothesis testing and steps in hypothesis testing - traditional method. } \\
\text { 2. With the steps given, let the learners identify key concepts they know a little, } \\
\text { know a lot and totally do not know about. }\end{array}$ \\
\hline
\end{tabular}


Evaluate:

Learners will answer question about the meaning of hypothesis testing, the steps involved in hypothesis testing, as well as as its importance.

2.Statistical Hypothesis
Engage/Explore (Relating): My Mobile Legend Stats

1. Learners will have some sharing about their ML stats and answer some questions: Win Rate, KDA = (Kills + Assists) / Deaths, MVP Rate $=(m v p+m v p$ from losing team $) /$ matches $* 100 \%$

2. In groups, allow students to make a CLAIM about the average win rate of CSHS students on ML. They must also answer, "How may hypothesis testing help you provide evidence for their claims?"

3. The steps in hypothesis testing will be reviewed.

Explain (Relating, Cooperating):

1. Definitions of null and alternative hypotheses will be discussed in the context on claims on the average win rate of CSHS students on ML.

3. Examples about absenteeism in senior high school, killings in the Philippines will be given.

4. $Q$ and $A$

Extend (Applying):

The average number of students who come to school late in a week is 43 . Suggest a policy that would make a significant change in this number. State your hypotheses when this policy is implemented.

Evaluate (Relating, Applying):

Let the students state the null and alternative hypothesis for a given situation. Also Identify the type of test involved.

3.Error and Engage (Relating): Is he Mr. Right?

Significance Level

Questions will be asked.

Discussion follows. Ask the students, "What mistakes may you have in deciding whether to reject Mr. X or not?

Explore (Cooperating):

Based on the photos given, definitions of Type I and Type II errors will be formulated by groups.

Explain (Relating):

Discuss errors further. Significance level will be discussed by giving the trial decision error example. Students shall be asked to volunteer as judge and defendant.

Extend (Relating):

Another example will be given in the context of opening a food business.

Evaluate (Applying):

SAFETY. 
4.Test Value

\section{Engage/Explore (Relating):}

Reflection about the last post on Facebook.

Quick Survey: What claims may be done using the data that we have? What values may be computed out of the data gathered? How can these be used in coming with a conclusion or decision?

\section{Explain (Experiencing):}

1. Formulas will be discussed.

2. Examples on absenteeism and killings will be given. Stat tester app will be used.

\section{Extend (Experiencing, Cooperating):}

In the social media use activity done in class, which test must be used?

Compute for the test statistic.

Evaluate (Applying):

Let the students identify the appropriate statistical test then compute for the test statistic for a given situation such as:

watching tv, sleeping hours, and use of phones.

\section{Critical Values and Rejection Regions}

\section{Engage (Relating)}

Post a statement.

Ask the learners: From whom do you often here this? What does this mean?

\section{Explore (Cooperating):}

In groups of 5, allow students to recall among themselves how to use the z-table. Each group will be provided with the areas under the normal curve. They must look for the closest z-value for the corresponding areas.

Each group must present the values they got.

\section{Explain (Cooperating):}

Allow groups to discover where to get critical values given a specific problem or situation. Ask the students to: (i)State the hypotheses. (ii) What type of test is appropriate for this? (iii) Identify and illustrate the critical value/s and the rejection region/s.

\section{Extend:}

Illustrate the rejection regions in each situation.

Evaluate (Applying): Given a situation, the students will be asked the following (i) Write the hypotheses. (ii) What type of test must she use based on the hypotheses? (iii) What significance level must she use? (iv) Draw the diagram showing the critical or rejection regions.

\section{Making the} Decision
Engage (Cooperating):

A relay game will be played. After 30 seconds, students of each group will be transferring from one station to another. 


\section{Explore (Relating, Cooperating):}

The average score of STEM students will be given.

In groups, learners will then formulate hypothesis about the average score of Humanities and Social Sciences students as compared to STEM. Each group must then discuss the steps that must be done until the computation of test statistic and determination of critical values.

Allow learners to construct the idea that the critical and test values will be compared.

\section{Explain (Cooperating):}

Using the previous problem presented, allow groups to make the decision by just posting a statement and ask some questions about hypothesis testing and making decision.

Processing follows.

Extend (Applying):

Post a situation. Then $Q$ and $A$.

Evaluate (Applying, Cooperating):

Students must get the average number of absences per day during the first semester from their records. They shall then make a claim about their average number of absences per day during the second semester as compared to the first semester. The process of hypothesis testing will be conducted.

\section{Conducting a \\ Hypothesis Test \\ for One Sample Mean}

Engage (Relating): Smile

Watch "Just Smile". Students will be asked some questions.

\section{Explore (Experiencing, Applying, Cooperating):}

1. Quick survey on the number of times the students smile each day.

2. Conduct a hypothesis test given this set of data.

Explain/Extend (Relating):

Another example will be given. The theme is about killings in the Philippines.

Evaluate (Applying):

Improving Sales. $Q$ and A. Test hypothesis at a $5 \%$ significance level.

\section{Conducting a \\ Hypothesis Test \\ for One Sample \\ Proportion}

Engage (Relating):

Group activity

1. The learners will be asked to group themselves in terms of:

a. sex, b. favourite TV channel, c. favourite past time: TV viewing, internet use, mobile phone use

Explore (Relating):

1. Learners will be asked to give comments about the given news report.

2. Ask the learners.

3. Let the learners analyse the answers of others. 
Explain (Cooperating):

Given the formulas, definitions given to them, they must be able to explain to the class the similarities and differences in conducting a hypothesis test for one sample mean and one sample proportion.

Extend (Experiencing):

Consider the claim made by the students in the TV viewing report. Conduct a hypothesis test at $5 \%$ significance level.

Evaluate (Cooperating, Applying):

The infographics showing smoking statistics in the Philippines will be presented. In groups of 5, plan a hypothesis test for one sample proportion using one of the values given. The following steps must be followed: (i)Define the population under study. (ii) State the hypotheses that will be investigated. (iii) Give the significance level. (iv) Select a sample from a population.

(v) Collect data. (vi) Perform the calculations required for the statistical test. (vii) Make a conclusion.

Final Task

Evaluate (Transferring):

Let the students identify a specific phenomenon. With this, search for studies or survey results that relate to it. The topic they will be choosing must be related to their preferred career in the future. Have their initial hypothesis given what they have researched. Then, conduct the appropriate test.

Following the same suggested steps in evaluate part. The process involved and the results of their study must be presented through an infographic. This shall be presented orally to the class.

As for the control group, direct instruction was implemented. Direct instruction focuses on a sequenced and incremental mastery of curriculum-based competence and a capacity to apply generalizable skills (Liem \& Martin, 2013) in teaching concepts. It relies much on explicit delivery of lecture by the teacher. The study followed the seven steps in the implementation of DI (Liem \& Martin, 2013). These included setting objectives, assessment of prior knowledge, presentation of lesson through clear instruction, checking of understanding by giving examples, guided practice, processing of performance, and finally independent practice is given (see Table 2). 
Table 2. General structure of the direct instruction implementation

\begin{tabular}{ll}
\hline Activity & Description \\
\hline $\begin{array}{l}\text { Giving the objectives of the } \\
\text { lesson }\end{array}$ & $\begin{array}{l}\text { The objectives which are derived from the curriculum guide are } \\
\text { presented to the class. }\end{array}$ \\
Review of previous lesson & $\begin{array}{l}\text { Review of concepts, formulas and definitions are done through } \\
\text { recitation. } \\
\text { Definitions, concepts and steps are directly given to the students. } \\
\text { This is also when demonstration by teacher is done. }\end{array}$ \\
Guided Practice & $\begin{array}{l}\text { A problem or example is solved by the class with help of the } \\
\text { teacher. Then solutions are presented. } \\
\text { Individual Practice }\end{array}$ \\
Another example is solved by the class without the assistance of \\
the teacher. Then solutions are presented. \\
Problems that are similar to the practice problems are given. Then \\
solutions are presented. \\
Quinal Task
\end{tabular}

The experimental and control groups received contextualized and direct instructions respectively. Examples and problems included were derived from a Statistics book by Prentice Hall. Moreover, there were no group activities done in class, while all sessions were more of a lecture type of instruction. They were given formulas which they applied to a word problem. Unlike with contextualized instruction when a performance task was conducted, with direct instruction, a quiz was administered.

\subsection{Data analysis}

Descriptive statistics such as mean, median, standard deviation and percentage were used in analysing the attitudes and achievement of the students. To get the SATS scores, the average of the ratings given by the students in each item under each aspect was obtained.

Attitudes and achievement were analysed and compared to the results in the pretest using the Wilcoxon Sign test, Mann Whitney U and independent and dependent $\mathrm{t}$ tests respectively. A sign test makes one determine the difference in the number of times one group score higher than those in the other group (Fraenkel et al., 2011).

To analyse and compare the pre and post test scores, t-test for dependent samples was utilized. The mean percentage scores of the experimental and control groups were analysed by utilizing t test for independent samples. 
Finally, responses to the interview were transcribed verbatim and were carefully analysed. Themes were formulated from these in order to give a summary of the general attitude of the students towards the topics taught to them.

\section{Results and discussion}

\subsection{Pre-test results of students" attitudes towards learning statistics}

In general, prior to the implementation of instructions involving hypothesis testing, students from both the control and experimental groups have positive attitude towards statistics in terms of value, interest and effort as shown in Table 3. Furthermore, effort as an attitude had the highest mean for both control and experimental groups with mean values 5.48 and 5.68 respectively. This is followed by interest $(\overline{\mathrm{x}}=5.25 ; \overline{\mathrm{x}}=5.39)$, while value got the lowest $(\overline{\mathrm{x}}=5.12 ; \overline{\mathrm{x}}=5.14)$. Students believed that they have been exerting effort towards the subject such as in doing their tasks, exercises and attending class. From the interviews conducted, a student mentioned, "I do what has to be done and it's okay". Other positive response includes how they show interest by saying, "I like statistics because it was taught well, and I like computing."

Table 3. Attitude of students towards statistics

\begin{tabular}{llllllll}
\hline Attitude & \multicolumn{2}{c}{ Control Group } & \multicolumn{2}{l}{ Experimental Group } & Overall & & \\
& Mean & SD & Mean & SD & Mean & SD & Description \\
\hline Value & 5.12 & 0.80 & 5.14 & 0.83 & 5.13 & 0.81 & positive \\
Interest & 5.25 & 0.68 & 5.39 & 0.77 & 5.32 & 0.73 & positive \\
Effort & 5.48 & 0.79 & 5.68 & 0.83 & 5.58 & 0.81 & positive \\
\hline
\end{tabular}

Range: 0.00-3.50 Negative attitude; 3.51-4.49 Neutral; 4.50-7.00 Positive attitude

Overall, only one student had negative attitude towards statistics in terms of value, interest, and effort. Seventy-two percent valued statistics positively. Majority were also positive in terms of interest and effort with 82 percent and 94 percent respectively. These results agree with the study of Coetzee and Merwe (2010) in South Africa where students displayed high level of interest in understanding and learning, valued statistics and were willing to work hard for the subject. Despite these students perceived statistics as a difficult subject, they were willing to put some effort to become successful in the subject. 
Results showed that majority of the students valued statistics. This means that students valued the subject as it is useful in life. They also believed that skills and knowledge taught to them may be relevant to their future jobs. Majority of the students were also positive about their interest towards the subject. They were interested in learning, understanding, and using the concepts in statistics. Finally, the students showed a positive attitude towards the subject in terms of effort. They completed requirements and gave ample time for studying statistics.

The students from both groups were also handled by the researcher prior to the conduct of the study. This may indicate that the students have already built a positive attitude towards the subject previously.

Other factors that could have influenced the students' attitudes were predicted by motivation-related variables where teachers and peer support were found to be highly significant in understanding these attitudes (Mata et al., 2012). These factors cited may have influenced the respondents of the study prior to the implementation of the developed instruction.

Hypothesis testing or statistics can be too abstract. Therefore, it is taught considering it as a means, not an end. This indicates that it must be taught in the context of real world. With direct instruction, elements of constructivism and collaboration were not present but, in both instructions, applications were done. This may have contributed to the similarity of the attitudes towards statistics by both groups.

Other than type of instruction, several factors affect student attitudes. Some of which are teacher characteristics and attitudes, pressure, and peer support (Mata et al., 2012). The teacher's attitude shown in class greatly affects students' attitudes towards the subject. The same amount of support was provided to both groups. Students feel more positive when support from the teacher and peers is present.

\subsection{Students' attitudes towards statistics after the implementation of contextual teaching}

Table 4 shows that the attitudes of students in the experimental group remained positive in terms of value, interest and effort as indicated by the median scores. SATS post scores in interest and effort have increased. Effort remained to be the highest $(M d n=5.72, R=2.8)$, followed by interest $(M d n=5.48, R=3.5)$ and value $(M d n=$ $5.29, R=3.0)$. 
Table 4. Pre and post-test results of students' attitude towards statistics

\begin{tabular}{|c|c|c|c|c|c|c|}
\hline \multirow[b]{2}{*}{ Attitude } & \multicolumn{2}{|c|}{ Pre Test } & \multicolumn{2}{|c|}{ Post Test } & \multirow[t]{2}{*}{$z$} & \multirow[t]{2}{*}{$p$} \\
\hline & Mdn & $\mathrm{R}$ & Mdn & $\mathrm{R}$ & & \\
\hline Value & 5.00 & 3.34 & 5.29 & 3.0 & 1.12 & 0.26 \\
\hline Interest & 5.45 & 2.76 & 5.48 & 3.5 & 1.07 & 0.29 \\
\hline Effort & 5.65 & 4.42 & 5.72 & 2.8 & 0.28 & 0.78 \\
\hline
\end{tabular}

*Significant at $\alpha=0.05$

Wilcoxon Signed Rank Test results showed that the difference in the pre and post SATS median scores were not significant in terms of value, interest and effort. This means that there was no significant increase nor decrease in the SATS scores of students who were taught using contextualized instruction. It must be noted that prior to the implementation of contextualized instruction, students had already positive attitude towards statistics. Hence, a small increase is found to be not significant. This supports the findings of Suryawati and Osman (2018), who tested the effectiveness of CTL and found no difference in terms of scientific attitude in Natural Science among Junior school students in Pekanbaru, Indonesia.

Statistics has been disliked by non-statisticians. Memorizing formulae is a potential reason that students have for disliking statistics (Altintas \& Ilgün, 2017; Ramsey, 1999). What happens is they are asked to memorise formulae to be used in problems provided by the teacher. This is what the CTL is trying to avoid. Instead of focusing on the memorization of formulae, teachers activate the previous knowledge of students in order to create a new one through group activities. After which, the students use newly learned or constructed concepts in examples and exercises which are relevant to them.

With the implementation of the CTL guide, a student commented, "It's okay that formulae are not memorized, so we can focus with the computations."

These students in the experimental group were provided with meaningful and collaborative activities using contextualized instruction. Through contextualized instruction, students maintained positive attitudes towards the subject. In the interview, students said, "When teachers give examples, we can relate. The more we can relate with the examples, the more we learn." With examples that they can relate with such as social media and online games they get attracted to listen; as mentioned by another student, "Others were attracted to listen."

They valued and were interested in learning statistics. From the interviews, it was found out that the decision-making topic for them is the one that they think is very 
important in real life. For them, this skill is crucial in the future. Students find the topics interesting because they can relate to them. One example is the use of social media. They also mentioned about the examples being informative. They tend to learn more aside from the topics in statistics with the examples and activities given to them. Through the contextualized instruction, students value and make meaning to what they learn (Mouraz \& Leite, 2013). In giving examples, hobbies and preferred college course were considered, thus making the students more interested in class. With assessment, Baker, Hope, and Karandjeff (2009) stated that an authentic context helps the learners see the relevance of information and creates a pathway for them to understand the material. This was done through actual data gathering and analysis regarding the topic of their interest. This contributes to the positive attitude they have towards statistics.

They also exerted effort towards the accomplishment of tasks. These results agree with Suryawati, Osman and Meerah (2010) that as learning becomes more cooperative and challenging, students exert effort in completing the tasks. The students find the performance task of actual data gathering and analysis activity interesting at the same time challenging. They enjoyed going after respondents to be surveyed. Moreover, they get to know and get along with students from other classes.

In terms of cooperative learning as one of the underlying principles of CTL, they find group activities positive as they get to help and be helped by their classmates. As in Suryawati, et al (2010), learning becomes more cooperative. Elements of cooperation were found to be evident while they learn in groups and when they communicate with each other.

\subsection{Students' achievement in hypothesis testing before the implementation of contextual teaching and learning}

Prior to teaching hypothesis testing, the students had a very low achievement in terms of mean percentage score. On the average, the mean percentage score is 18.4 which was below mastery level as shown in Table 5 .

Table 5. Pre-test results of students' achievement in hypothesis testing

\begin{tabular}{llll}
\hline Group & Mean & SD & Description \\
\hline Control & 17.7 & 6.50 & Below Mastery \\
Experimental & 19.1 & 8.40 & Below Mastery \\
Overall & 18.4 & 7.50 & Below Mastery \\
\hline
\end{tabular}

Range: 60 and below-Below Mastery; 61-79-Moving Towards Mastery; 80 and above- Mastered 
The topic was taught only during the fourth quarter; thus students have very limited knowledge about it. Hypothesis testing is a unit covering topics involving one sample mean and one sample proportion. Required prior knowledge on reading $\mathrm{z}$ and $\mathrm{t}$ values from tables had been discussed but were also part in the unit of hypothesis testing. Other than these topics, concepts were relatively new to the students.

\subsection{Students' achievement in hypothesis testing after the implementation of contextual teaching}

Results of paired t-test for dependent samples revealed a significant difference in the mean scores of experimental group students between the pre-test and post-test (Table 6). In particular, the students significantly scored higher in the post-test $(M=61.2$, $S D=8.65)$ than in the pre-test $(M=19.1, S D=8.40)$, t $(36)=18.3, \mathrm{p}=0.00)$. Using the teaching guide developed by the researcher, the student achievement had improved to moving towards mastery level. Although findings in the control group also showed significant difference in the mean scores of the students between pre-test and post-test, but the increase was not that high and still in the below mastery level as compared to the increase observed in the experimental group. This affirms the findings of Surya, and Saragih (2017) who found positive results in the use of CTL in mathematics; Haryanto and Arty (2019) and Suryawati and Osman (2018) who tested the effectiveness of CTL and found significant difference on the achievement in Natural Science; Syahputri and Mariyati (2019) who found significant improvement of the students' achievement in reading comprehension by applying CTL; Shodiq and Ihsan (2017) who found significant improvement in the achievement of students in Basic Grammar Class; and Qudsyi, Wijaya and Widiasmara (2017) who in the same manner found CTL as an effective way of improving the students achievement in Cognitive Psychology Course.

Table 6. Pre and post test scores of experimental group

\begin{tabular}{lcccc}
\hline Mean Percentage Score & $\mathrm{M}$ & $\mathrm{SD}$ & $\mathrm{t}$ & $\mathrm{p}$ \\
\hline Experimental Group & & & & \\
Pre-Test & 19.1 & 8.40 & & \\
Post Test & 61.2 & 8.65 & 18.3 & $0.00^{* *}$ \\
Control Group & & & & \\
Pre-Test & 17.7 & 6.50 & & \\
Post Test & 39.9 & 14.0 & 2.03 & $0.00^{* *}$ \\
\hline
\end{tabular}

**Significant at 0.00 
The post test results in the researcher-made test were compared. Results of the independent $t$ test (Table 7) reveal a significant difference in the mean scores between the and experimental and control groups $(\mathrm{t}(72)=3.75, \mathrm{p}=0.00)$ In particular, students who were taught using contextualized instruction scored higher $(M=61.2, S D=8.65)$ than the students who were taught using direct instruction $(M=39.9, S D=14.0)$.

Table 7. Post test scores of the control and experimental group

\begin{tabular}{lllll}
\hline Mean Percentage Score & $\mathrm{M}$ & $\mathrm{SD}$ & $\mathrm{t}$ & $\mathrm{p}$ \\
\hline Control Group & 39.9 & 14.0 & & \\
Experimental Group & 61.2 & 8.65 & 3.75 & $0.00^{* *}$ \\
\hline
\end{tabular}

**Significant at 0.00

Results agree with Selvianiresa and Prabawanto, (2017), where students learn better through contextualized instructions than direct instruction. Both results show that CTL learning can be more effective when there is collaborative interaction, and connection to real-world contexts. One example is the use of business example as mentioned by a student. In the future, they already have the idea if they wish to start a business while learning errors in statistics. Another student mentioned that the more they can relate to the topic, the more they learn. Other related studies show similar results and conclude that with contextualized instruction, students learn better. Valenzuela (2018) suggested that students understand problems successfully when they can relate with them. Finally, Mam, Domantay, and Rosals (2017) also concluded that students learn statistics better when students are exposed to contextualized and indigenized teaching.

\section{Conclusions}

This study provided evidence on how contextual teaching promotes the learning of statistical hypothesis testing. Though the students already have a positive attitude towards statistics even before the implementation of contextual teaching, such attitude was heightened after the implementation of contextual teaching. They find the experience interesting and challenging at the same time. Students learned hypothesis testing through contextual teaching with low mastery. Moreover, students learn better with contextualized instruction than direct instruction.

With these, contextualized instruction must be promoted in teaching statistics. Instead of teaching students using plain lecture methods, more relevant and 
constructivist activities must be provided. Applications must also be done in context where they can relate with.

The study affirmed the potential of the implementation of contextual instructions in teaching and learning statistics, thus the REACT (relating, experiencing, applying, cooperating, transferring) strategies used are recommended. In designing lesson plans, the following strategies are suggested to be intensified:

1. Use of real-life examples. Examples used in class must be within the context or background of the students so that they may be able to relate to them. These could be their hobbies, preferred course or future careers. Data to be used in class must also be timely, thus reports found online may be utilized.

2. More hands-on activities. Students must also be given hands-on activities through real-life exercises where they can apply the concepts learned. They must be given set of exercises which are in context of real-life situations. With this, actual data may be gathered through quick surveys in class. This may then be analysed or used for students to practice the skill being taught to them.

3. Collaborative activities. There must also be activities that promote collaboration. Providing performance task where students are involved in real data gathering and analysis activities are also recommended. Students must be allowed to think of their own topic of interest to be investigated. In this case, students are given opportunities to negotiate and interact with their learning partner or group mates.

4. Authentic assessment. Finally, an authentic assessment is recommended in statistics. In this case, it may be connected to a research activity where students get to test hypothesis based on a topic of their interest. In addition, they are to experience the rigor of data collection.

Studying and learning statistics is quite challenging, especially for students who find no affinity in numbers. But no one can deny its importance as everyone lives in this information world, and much of this information is determined mathematically by statistics. Guided by this reality is a responsibility for subject teachers to find better and efficient ways on how learning statistics would be enjoyable and exciting. By linking it to the real world, students would be able to view statistics as more than just a subject. Thus, teachers will find their way to succeed in facilitating learning in statistics. 


\section{References}

Altintas, E., \& Ilgün, S. (2017). Exploring the Opinions about the Concepts of" Formula" and" Rule" in Mathematics. Educational Research and Reviews, 12(19), 956-966. https://doi.org/10.5897/ERR2017.3349

Ambrose, V. K., Davis, C. A., \& Ziegler, M. F. (2013). A framework of contextualized teaching and learning: Assisting developmental education instructors. https://newprairiepress.org/aerc/2013/papers/1/

Bybee, R. W. (2014). The BSCS 5 E instructional model: Personal reflections and contemporary implications. Science and Children, 51(8), 10-13.

https://www.ksta.org/resources/Documents/Resources/The\%20BSCS\%205E\%20Instructi onal\%20Model_Bybee\%20article.pdf

Baker, E. D., Hope, L., \& Karandjeff, K. (2009). Contextualized Teaching \& Learning: A Promising Approach for Basic Skills Instruction. Research and Planning Group for California Community Colleges (RP Group). https://eric.ed.gov/?id=ED521932

Bird, D., Livesey, G. \& Simon, P. (n.d.). The Integration of Academic and Technical Skills in K-12 and Community College Classrooms: Contextualized Teaching and Learning as a Key Strategy. Retrieved 20 August 2019 https://www.careerladdersproject.org/wpcontent/uploads/2011/05/ContextualizedTeaching-and-Learning-as-a-Key-Strategy.pdf

Carbonaro, W. (2005). Tracking, students' effort, and academic achievement. Sociology of Education, 78(1), 27-49. https://doi.org/10.1177\%2F003804070507800102

Coetzee, S., \& Merwe, P. V. D. (2010). Industrial psychology students' attitudes towards statistics. SA Journal of Industrial Psychology, 36(1), 1-8.

http://www.scielo.org.za/scielo.php?script=sci_arttext\&pid=S2071-07632010000100009

Crawford, M. L. (2001). Teaching contextually. Research, Rationale, and Techniques for Improving Student Motivation and Achievement in Mathematics and Science. Texas: Cord. https://www.collins-tips.com/distance-ed/crawford.pdf

Duru, A. (2010). The experimental teaching in some of topics geometry. Educational Research and Reviews, 5(10), 584-592. https://doi.org/10.5897/ERR.9000354

Fraenkel, J. R., Wallen, N. E., \& Hyun, H. H. (2011). How to design and evaluate research in education. New York: McGraw-Hill Humanities/Social Sciences/Languages.

Gal, I., Ginsburg, L., \& Schau, C. (1997). Monitoring attitudes and beliefs in statistics education. The assessment challenge in statistics education, 12, 37-51. https://www.stat.auckland.ac.nz/ iase/publications/assessbk/chaptero4.pdf

Garfield, J. (1995). How students learn statistics. International Statistical Review/Revue Internationale de Statistique, 25-34. https://doi.org/10.2307/1403775

Haryanto, P. C., \& Arty, I. S. (2019). The Application of Contextual Teaching and Learning in Natural Science to Improve Student's HOTS and Self-efficacy. In Journal of Physics: Conference Series (Vol. 1233, No. 1, p. 012106). IOP Publishing.https://iopscience.iop.org/article/10.1088/1742-6596/1233/1/012106/meta

Hidayah, A. N. (2017). The Influence of Contextual Teaching and Learning Approach on Students' Writing Descriptive Text (A Quasi-experimental Study at the Seventh Grade Students of SMP Fatahillah Ciledug, Tangerang) (Bachelor's thesis).

Hommik, C., \& Luik, P. (2017). Adapting the Survey of Attitudes towards Statistics (SATS-36) for Estonian Secondary School Students. Statistics Education Research Journal, 16(1). https://iase-web.org/documents/SERJ/SERJ16(1)_Hommik.pdf

Johnson, E. B. (2002). Contextual teaching and learning: What it is and why it's here to stay. Corwin Press. 
Karabiyik, C., \& Mirici, I. H. (2018). Development and Validation of the Foreign Language Learning Effort Scale for Turkish Tertiary-Level Students. Educational Sciences: Theory and Practice, 18(2), 373-395. https://eric.ed.gov/?id=EJ1201845

Kim, S., Jiang, Y., \& Song, J. (2015). The effects of interest and utility value on mathematics engagement and achievement. Interest in mathematics and science learning, 63-78.

Larwin, K., \& Larwin, D. (2011). A meta-analysis examining the impact of computer-assisted instruction on postsecondary statistics education: 40 years of research. Journal of Research on Technology in Education, 43(3), 253-278.

https://doi.org/10.1080/15391523.2011.10782572

Liem, G.A.D., \& Martin, A.J. (2013). Direct instruction and academic achievement. In J. Hattie \& E. Anderman (Eds.). International Guide to Student Achievement. Oxford: Routledge. Retrieved from https://www.researchgate.net/publication/281156143_Direct_instruction.

Mam, R. M. G., Domantay, G. F., \& Rosals, J. (2017). Contextualized and Localized Teaching as a Technique in Teaching Basic Statistics.

Mata, M. D. L., Monteiro, V., \& Peixoto, F. (2012). Attitudes towards mathematics: Effects of individual, motivational, and social support factors. Child development research, 2012. https://downloads.hindawi.com/archive/2012/876028.pdf

Mazzeo, C., Rab, S. Y., \& Alssid, J. L. (2003). Building Bridges to College and Careers: Contextualized Basic Skills Programs at Community Colleges. https://eric.ed.gov/?id=ED473875

Mensah, J. K., Okyere, M., \& Kuranchie, A. (2013). Student attitude towards mathematics and performance: Does the teacher attitude matter. Journal of Education and Practice, 4(3), 132-139.

Misteni, M., \& Baehaqi, L. (2016, June). Effects of teaching vocabulary mastery by contextual teaching and learning. http://english.ftik.iain-palangkaraya.ac.id/

Mouraz, A., \& Leite, C. (2013). Putting knowledge in context: Curriculum contextualization in history classes. https://repositorio-aberto.up.pt/bitstream/10216/76847/2/94192.pdf

Panayides, P. (2013). Coefficient alpha: Interpret with caution. Europe's Journal of Psychology, 9(4), 687-696. https://doi.org/10.5964/ejop.v9i4.653

Perin, D. (2011). Facilitating student learning through contextualization: A review of evidence. Community College Review, 39(3), 268-295.

https://doi.org/10.1177\%2F0091552111416227

Pintrich, P.R., \& Schunk, D.H. (1996). Motivation in Education: Theory, Research, and Application. New Jersey: Prentice Hall.

Prayoga, T., \& Abraham, J. (2017). A psychological model explaining why we love or hate statistics. Kasetsart Journal of Social Sciences, 38(1), 1-8.

https://doi.org/10.1016/j.kjss.2016.08.013

Qudsyi, H., Wijaya, H. E., \& Widiasmara, N. (2017). Effectiveness of Contextual Teaching and Learning (CTL) to Improve Students Achievement and Students' Self-Efficacy in Cognitive Psychology Course. In International Conference on Learning Innovation (ICLI 2017). Atlantis Press. https://dx.doi.org/10.2991/icli-17.2018.27

Ramsey, J. B. (1999). Why do students find statistics so difficult? Proceedings of the 52nd Session of the ISI. Helsinki, 10-18. https://iase-web.org/documents/papers/isi52/ramsoo70.pdf

Rosenthal, J. S. (1995). Active learning strategies in advanced mathematics classes. Studies in Higher Education, 2O(2), 223-228. https://doi.org/10.1080/03075079512331381723

Schau, C., Stevens, J., Dauphinee, T. L., \& Vecchio, A. D. (1995). The development and validation of the survey of attitudes toward statistics. Educational and Psychological Measurement, 55(5), 868-875. https://doi.org/10.1177\%2Fo013164495055005022 
Seier, E., \& Joplin, K. H. (2010). Teaching Statistics in the context of biology: The symbiosis experience. In Data and context in statistics education: Towards an evidence-based society. Proceedings of the Eighth International Conference on Teaching Statistics (ICOTS8. https://www.stat.auckland.ac.nz/ iase/publications/icots8/ICOTS8_C176_SEIER.pdf

Selvianiresa, D., \& Prabawanto, S. (2017). Contextual teaching and learning approach of mathematics in primary schools. In Journal of Physics: Conference Series (Vol. 895, No. 1, p. 012171). IOP Publishing. https://iopscience.iop.org/article/10.1088/17426596/895/1/012171/meta

Shodiq, A., \& Ihsan, A. (2017). The Effectiveness of Contextual Teaching and Learning to Improve Achievement in Basic Grammar Class at Kampung Inggris Language Center Pare Kediri. UI Proceedings on Social Science and Humanities, 1. http://proceedings.ui.ac.id/index.php/uipssh/article/view/61

Surya, E., \& Saragih, S. (2017). Development of Learning Devices Based on Contextual Teaching and Learning Model Based on the Context of Aceh Cultural to Improve Mathematical Representation and Self-efficacy Ability of SMAN 1 Peureulak Students. Journal of Education and Practice, 8(27), 186-195. http://iiste.org/Journals/index.php/JEP/article/view/38939

Suryawati, E., \& Osman, K. (2018). Contextual learning: Innovative approach towards the development of students' scientific attitude and natural science performance. Eurasia Journal of Mathematics, Science and Technology Education, 14(1), 61-76. https://doi.org/10.12973/ejmste/79329

Suryawati, E., Osman, K., \& Meerah, T. S. M. (2010). The effectiveness of RANGKA contextual teaching and learning on students' problem-solving skills and scientific attitude. ProcediaSocial and Behavioral Sciences, 9, 1717-1721. https://doi.org/10.1016/j.sbspro.2010.12.389

Syahputri, D., \& Mariyati, P. (2019). Improving Students' Achievement in Reading Comprehension by Applying Contextual Teaching and Learning (CTL). Budapest International Research and Critics in Linguistics and Education (BirLE) Journal, 2(3), 58-69. https://doi.org/10.33258/birle.v2i3.361

Syatriana, E. (2013). A Model of Creating Instructional Materials Based on the School Curriculum for Indonesian Secondary Schools. https://doi.org/10.31219/osf.io/z8gf9

TeacherPH. Professional Learning Online Community of Teachers and for Teachers. (2020). Statistics and Probability: Senior High School SHS Teaching Guide. Retrieved 29 July 2020 from https://www.teacherph.com/statistics-probability-senior-high-school-shs-teachingguide/

Valenzuela, H. (2018). A Multiple Case Study of College-Contextualized Mathematics Curriculum. Online Submission, 9(2), 49-55. https://eric.ed.gov/?id=ED581241

Wild, C. J., Utts, J. M., \& Horton, N. J. (2018). What is statistics? In International handbook of research in statistics education (pp. 5-36). Springer, Cham. https://doi.org/10.1007/978-3319-66195-7_1

Zieffler, A., Garfield, J., Alt, S., Dupuis, D., Holleque, K., \& Chang, B. (2008). What does research suggest about the teaching and learning of introductory statistics at the college level? A review of the literature. Journal of Statistics Education, 16(2). https://doi.org/10.1080/10691898.2008.11889566 